Borneo Journal of Sciences \& Technology, 3(2): 16-19

DOI: http://doi.org/10.3570/bjost.2021.3.2-03

e-ISSN: 2672-7439

(c) 2018, UCTS Publisher.

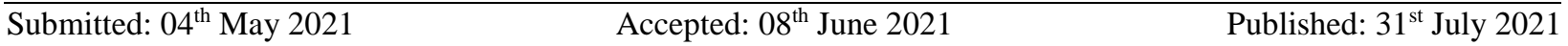

\title{
Occupational Accidents in Forestry and Agricultural Sectors in Malaysia
}

\author{
${ }^{1}$ Noor Jemali, ${ }^{1}$ Syafinie Majid, ${ }^{1}$ Marinah Muhammad, ${ }^{1}$ Najidah Mustafa, ${ }^{2}$ Juliana Yahya \\ and ${ }^{3}$ Nasrul Akmal Amaludin
}

\author{
${ }^{1}$ Faculty of Earth Science, Universiti Malaysia Kelantan 17600 Jeli, Kelantan, Malaysia \\ ${ }^{2}$ Forestry Department of Peninsular Malaysia, Jalan Sultan Salahuddin, 50660 Kuala Lumpur, Malaysia \\ ${ }^{3}$ Terengganu Forestry Training Centre, 21700 Kuala Berang, Terengganu, Malaysia
}

\begin{abstract}
The forestry and agriculture sector is the second dangerous industry after the manufacturing sector. By years, fatal death, permanent disability (PD) and non-permanent disability (NPD) accident cases were reported to DOSH and SOCSO include incidents involving activities in the agriculture and forestry sectors. This paper aimed to discover the frequency and trend of workplace accidents from 2016 to 2020. The database used was documents and reports from government and private agencies including from the Social Security Organization (SOCSO), Department of Occupational Safety and Health (DOSH), as well as information from journals and newspaper reports. The trend of workplace accidents showed an increasing pattern within 5 years. Based on the analysis, $14.4 \%$ of total workplace accidents reported in Malaysia was from the forestry and agriculture sector. On average, 778 accident cases were reported per year, majorly non-permanent disability cases $(93.9 \%), 1.9 \%$ of permanent disability and $4 \%$ of death cases. The findings of this study are expected to be useful to all relevant authorities in the decision-making process and strategic plans specifically for the agriculture and forestry sectors in mitigating and reducing workplace hazards and injuries.
\end{abstract}

Keywords: forestry accident, safety, OSH, workplace hazard, fatality rate.

\section{INTRODUCTION}

Employee safety is one of the most important issues that industries should be concerned about because they are the people who often drive the operations and success of an industry. In Malaysia, based on the Department of Occupational Safety and Health (DOSH) there are ten main sectors of industries that have been classified such as construction, mining, manufacturing etc. Every year, fatal death, permanent and non-permanent disability accident cases were reported to DOSH and SOCSO include incidents involving agriculture, forestry and fisheries sectors.

Agriculture industries in Malaysia covered 7.9 million hectares with various agricultural production, of which palm oil, sugar, and rubber are the most important commodities. Agriculture is a significant industry in terms of job creation which accounting for $12 \%$ of the population and employing nearly 1.7 million people in 2014 [1]. Meanwhile, in the forestry and timber sector, about 122,513 people are employed formally, with another thousand more employed informally, particularly in the small timber production industry [1];[2].
Either in the agriculture or forestry sectors, many workers receive little or no training. Accidents should be seen as preventable, not inevitable. Nevertheless, the difficult circumstances commonly found in forestry work mean that accidents are more likely than in most other sectors which in Malaysia this sector has count as the second-highest workplace accident after the construction industry. Even though many workplace accidents reported in Malaysia annually, less is known on the specific accident cases that happen in agriculture, forestry and fishery activity. Therefore, this paper intended to discover the workplace accidents reported by private and government agencies and focus on the occupational accident happen in agriculture and forestry sectors.

\section{MATERIALS AND METHODS}

In this analysis we used the database of the various sources on workplace accidents statistics include from Social Security Organization (SOCSO), Department of Occupational Safety and Health (DOSH), online reports and newspaper reports. Data gathered was tabulated and analyzed descriptively on its trend and rate of

Corresponding Author: Noor Janatun Naim Jemali, Faculty of Earth Science, Universiti Malaysia Kelantan (UMK)

Email: janatunnaim@umk.edu.my 
occupational accidents that happen between the years 2016 and 2020. Data were analyzed using data mining methodology. Information from accident reports was extracted and transformed into an understandable structure i.e. frequency of the accidents and trends by year based on the major cause of accidental cases reported from the data provider.

\section{RESULTS AND DISCUSSION}

There are ten main industries categorized by the DOSH and SOCSO as shown in Table 1. Among listed, the manufacturing sector shows the highest rate of accidents occurred with an average of 3435 cases/year within 2016-2020. It is followed by agriculture, forestry and fishery sectors, while the less reported workplace accident cases were from the quarrying and mining industry. Based on the frequency analysis of the workplace accidents reports, the current status of workplace accidents in Malaysia by states showed that Selangor exhibited the highest rate of occupational accidents cases with a total of 1697 accident cases reported in 2020 (Table 2). It is followed by Johor, Perak and Pulau Pinang whereby these are the main industrial states in Malaysia.

The detail of accident cases by industries include types of accidents of permanent disability (PD), nonpermanent disability (NPD) and death cases are shown in Figure 1. For example, in 2019, the workplace accident rate in 1000 workers is 2.71 with the total reported cases was 40811 (112 cases/day). Within this, the total fatality was 578 cases with a fatality rate of 2 cases per day whereby in 100,000 workers about 3.83 workers found died. Although total accident cases in Malaysia showed a declining trend with the manufacturing sector winning the chart, there is some discussion to focus on forestry, agriculture and fishery sector.
Table 2. Frequency of workplace accident by states in Malaysia

\begin{tabular}{lcccc}
\hline State & NPD & PD & DEATH & Total \\
\hline Selangor & 1595 & 69 & 33 & 1697 \\
Johor & 1273 & 25 & 38 & 1336 \\
Perak & 903 & 39 & 32 & 974 \\
P.Pinang & 805 & 22 & 21 & 848 \\
Pahang & 446 & 19 & 21 & 486 \\
N.Sembilan & 464 & 11 & 8 & 483 \\
Sarawak & 410 & 28 & 32 & 470 \\
Melaka & 361 & 9 & 8 & 378 \\
Sabah & 319 & 26 & 26 & 371 \\
Kedah & 299 & 19 & 8 & 326 \\
WPKL & 279 & 5 & 16 & 300 \\
Terengganu & 129 & 3 & 7 & 139 \\
Kelantan & 92 & 4 & 8 & 104 \\
Perlis & 43 & 0 & 1 & 44 \\
Labuan & 26 & 2 & 0 & 28 \\
\hline NPD: non-permanent disability & PD: Permanent disability
\end{tabular}

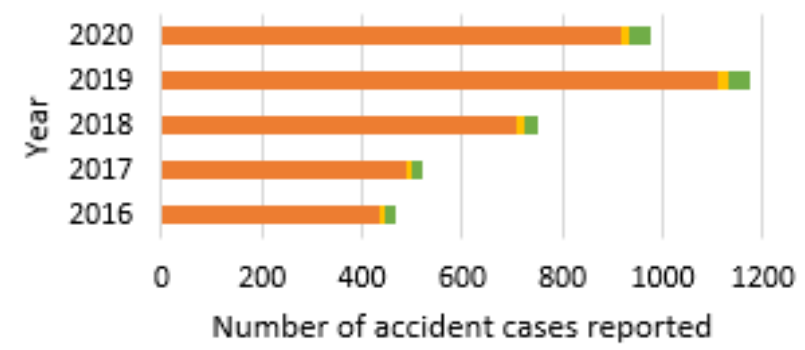

n Non-Permenant Disability $=$ Permenant Disability $\quad$ Death

Figure 1. Workplace acceded cases reported in 5 years by severity categories

Table 1. A five years workplace accident case based on industrial categories

\begin{tabular}{|c|c|c|c|c|c|c|}
\hline Sector & 2016 & 2017 & 2018 & 2019 & 2020 & Average \\
\hline Hotel and restaurant & 90 & 114 & 123 & 235 & 140 & 140.4 \\
\hline Utilities & 74 & 104 & 173 & 258 & 22 & 126.2 \\
\hline Finance, real estate, business service & 125 & 146 & 217 & 406 & 327 & 244.2 \\
\hline Construction & 222 & 240 & 232 & 326 & 206 & 245.2 \\
\hline Transport, communication & 127 & 122 & 137 & 389 & 311 & 217.2 \\
\hline Manufacturing & 2315 & 2178 & 3228 & 4948 & 4506 & 3435 \\
\hline Wholesale retail trade & 111 & 97 & 73 & 87 & 128 & 99.2 \\
\hline Public service & 110 & 66 & 58 & 99 & 77 & 82 \\
\hline Mining and quarry & 24 & 46 & 41 & 60 & 39 & 42 \\
\hline Agriculture, forestry and fishery & 467 & 522 & 749 & 1176 & 979 & 778.6 \\
\hline Total cases reported & 3665 & 3635 & 5031 & 7984 & 6735 & \\
\hline
\end{tabular}




\section{Occupational Accidents in Forestry and Agricultural Sectors in Malaysia}

Agriculture sectors cover activity such as establishments of growing crops, raising animals, while forestry and fishery sector generally entail harvesting timber, and harvesting fish respectively. The agricultural industry is the largest contributor to the national economy with the largest workforce of 1.5 million people, so do fishery sectors. The highest number of workers results in high risk and chances of occupational accidents occurred include the usage of machinery and hazardous materials used in specific sectors [3]. The forestry, agriculture and fishery sector made $14.2 \%$ of the total number of occupational accident cases every year. It marks this sector as the second-highest workplace accident reported in Malaysia. Table 3 show the workplace accidental cases in forestry, agriculture and fishery sector. Within five consecutive years, the average number of non-permanent disability (NPD) is 731 cases, while permanent disability and death are 15 and 32 cases respectively.

Table 3. Occupational accident in forestry, agriculture and fishery sector in 2016-2020

\begin{tabular}{lccccc}
\hline Accident type & $\mathbf{2 0 1 6}$ & $\mathbf{2 0 1 7}$ & $\mathbf{2 0 1 8}$ & $\mathbf{2 0 1 9}$ & $\mathbf{2 0 2 0}$ \\
\hline $\begin{array}{l}\text { Non-permanent } \\
\text { Disability }\end{array}$ & 435 & 488 & 709 & 1111 & 916 \\
Permanent & & & & & \\
Disability & 9 & 11 & 14 & 22 & 20 \\
Death & 23 & 23 & 26 & 43 & 43 \\
\hline Total & 467 & 522 & 749 & 1176 & 979 \\
\hline
\end{tabular}

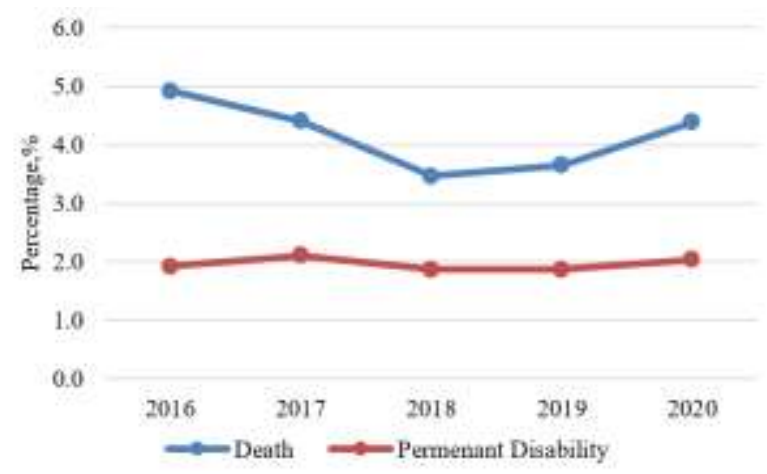

Figure 2. Permanent disability and death cases reported within 2016-2020 in forestry and agriculture sectors

The rate of fatality was analyzed at 32 cases per year, $4.2 \%$ of total cases reported in this sector. It was assumed that three death cases reported every month regardless of separation data between the agriculture and forestry sectors. Among the fatal cases recorded including falling off tractors, electrocuted, injured by oil palm fruit sickle and inhaled toxic gas while working in a confined space $[2,4]$. The major incident reported was non-permanent disability cases (94\%) with an average of 731 cases/year or 61 cases/month. Meanwhile, the rate of permanent disability resulted from a workplace accident in five years was 15 cases/year which account for $2 \%$ of the total cases in the agriculture and forestry sectors (Figure 2).

Based on the reported cases by the DOSH, the majority of the accidents happened as a result of a lack of adequate proper regarding machine operation work procedure. Many employees also are put at risk due to a lack of education and training, protection, and personal protective equipment (PPE). Any potential risks, in particular, are impossible to avoid and have endured over time, amid manufacturers' and engineers' attempts to provide safer designs [5];[6]. The minimum level of the employers' knowledge on occupational safety and health also the cause of the rising number of recorded cases. According to [7], despite the use of advanced machinery and technologies, agriculture and forestry remain one of the most dangerous sectors because employees are unaware and have a lack of proper preparation on safety culture at the workplace [8];[9]. Hence, few newspapers reported that most of the workplace accident cases occurred due to the failure of the employer to provide the latest and appropriate safety equipment as well as providing a safe working environment. Not to blame the employer, but many of them hesitant to lounge report to authorities on workers injuries due to failure to provide a safe and comfortable working environment [10];[11].

The goals of research and analyzing workplace accident reports are to improve employees' lives and to prevent workplace injuries and illnesses. From this study, we found that statistics on accidents in forestry are largely inadequate that lead to making comparisons and data aggregation so difficult. Those reliable data that do exist, but forestry-related work accident data are very scarce even though this sector is among the hazardous and risky profession [12]. A major impediment to accident reporting and analysis is the concern that it will lead to the apportioning of blame to individuals or organizations. It is recommended that for further study, specific data on accidents in each sector is collect in detail so that the actual rate and frequency could be determined. It is important to determine the core issues of the accidents at the same time, the data gathered may form an important database for DOSH to perform 
research and make strategic plans specifically for the agriculture and forestry sectors to ensure the validity of the statistical results.

\section{CONCLUSION}

Many workers are at risk due to inadequate education, training, and safety that contribute to the increasing number of workplace accidents in Malaysia. Data on specific sectors is needed for scientific research in creating a comprehensive action plan and improved operating procedures to minimize the accident risk in all industrial sectors. The agriculture and forestry sectors contribute $14.4 \%$ of the total workplace accident in Malaysia and the rate of accidents within these five years was at 65 cases/month. Collaborative efforts from employers and authorities in reporting occupational accidents is important for effective records to ensure the validity of the statistical results especially on injury detection and accident investigation to improve workers safety and health.

\section{ACKNOWLEDGMENT}

The authors are grateful for the data support from DOSH Malaysia, SOCSO and the Forestry Department of Peninsular Malaysia.

\section{REFERENCES}

[1] Department of Statistics. 2015. Number of Employed Persons by Industry, Labour Force Survey Time Series Data (1982-2014), accessed online at: https://www.dosm.gov.my/.

[2] Department of Occupational Safety and Health. Guidelines on Occupational Safety and Health in Agriculture.OSHA-UNDP Project 1999, 128pg.

[3] Yiha, O., and Kumie, A. 2010. Assessment of Occupational Injuries in Tendaho Agricultural Development S.C., Afar Regional State. Ethiopian Journal of Health Development, 24(3), 167-174.
[4] Zakaria, N. H., Mansor, N., and Abdullah, Z. 2012. Workplace Accident in Malaysia: Most Common Causes and Solutions. Workplace Accident in Malaysia: Most Common Causes and Solutions, 2(5), 75-88.

[5] Cole, H.P., Myers, M. L., and Westneat, S.C. 2006. Frequency and severity of injuries to operators during overturns of farm tractors. Journal of Agriculture Safety and Health, 12(2), 127-138.

[6] Melvin, L.M., Henry, P.C., and Susan, C.W. 2009. Injury severity related to overturn characteristics of tractors. Journal of Safety Research, 40(1), 165-170.

[7] Klun, J., and Medved, M. 2007. Fatal accidents in forestry in some European countries. Croatian Journal of Forest Engineering: Journal for Theory and Application of Forestry Engineering, 28, 55-62.

[8] Ackerknecht, C. 2015. Occupational safety indicators for forest operations, sawmilling and wood-based panels manufacture: An international benchmarking. Ciencia \& Trabajo, 17(53):89-98.

[9] Hui-Nee A. 2014. Safety Culture in Malaysian Workplace: An Analysis of Occupational Accidents. Health and Environment Journal, 5(3), 32-43.

[10] Isa, I. 2018. Lebih 200 kematian di tempat kerja. Berita Harian Online. Retrieved 2018, November

[11] Ismail, M. H. 2017. Sektor pembalakan masih pandang remeh soal keselamatan. Berita Harian,pp. 11 (June,12).

[12] Matsa, M., and Mandowa, J. 2015. Occupational safety and health problems in forest harvesting operations : Case of Wattle Company Nyanga Pine Estate, Zimbabwe, 4(4), 359-380. 